\title{
Influence of Silane Pretreatment and Warm Air-Drying on Long-Term Composite Adaptation to Lithium Disilicate Ceramic
}

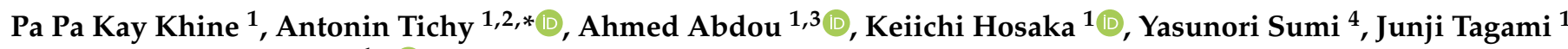 \\ and Masatoshi Nakajima ${ }^{1, *}$ (i)
}

1 Department of Cariology and Operative Dentistry, Graduate School of Medical and Dental Sciences, Tokyo Medical and Dental University, Tokyo 113-8510, Japan; papope@tmd.ac.jp (P.P.K.K.); ahmed.abdou@dnt.mti.edu.eg (A.A.); hosaka.ope@tmd.ac.jp (K.H.); tagami.ope@tmd.ac.jp (J.T.)

2 Institute of Dental Medicine, First Faculty of Medicine of the Charles University and General University Hospital in Prague, 12111 Prague, Czech Republic

3 Biomaterials Department, Faculty of Dentistry, Modern University for Technology and Information, Cairo 11571, Egypt

4 Center of Advanced Medicine for Dental and Oral Disease, National Center for Geriatrics and Gerontology, Department for Advanced Dental Research, Obu, Aichi 474-8511, Japan; yasusumi@ncgg.go.jp

* Correspondence: tichy.ope@tmd.ac.jp (A.T.); nakajima.ope@tmd.ac.jp (M.N.); Tel.: +81-3-5803-5483 (M.N.)

Citation: Kay Khine, P.P.; Tichy, A.; Abdou, A.; Hosaka, K.; Sumi, Y.;

Tagami, J.; Nakajima, M. Influence of Silane Pretreatment and Warm Air-Drying on Long-Term Composite Adaptation to Lithium Disilicate Ceramic. Crystals 2021, 11, 86. https://doi.org/10.3390/cryst11020086

Academic Editor: Raghvendra Singh Yadav

Received: 29 December 2020

Accepted: 18 January 2021

Published: 21 January 2021

Publisher's Note: MDPI stays neutra with regard to jurisdictional claims in published maps and institutional affiliations.

Copyright: (c) 2021 by the authors. Licensee MDPI, Basel, Switzerland. This article is an open access article distributed under the terms and conditions of the Creative Commons Attribution (CC BY) license (https:// creativecommons.org/licenses/by/ $4.0 /)$.

\begin{abstract}
Background: Repair bonding to lithium disilicate ceramic (LDS) remains an issue. This study examined whether the adaptation of a resin composite to LDS can be improved by a silane pretreatment and warm air-drying. Methods: LDS blocks (IPS e.max CAD) with prefabricated tapered cavities were bonded using a silane-containing universal adhesive (Clearfil Universal Bond Quick ER; UBQ) or the bonding agent of a two-step self-etch adhesive (Clearfil SE Bond 2), with and without a silane pretreatment (Clearfil Ceramic Primer; $\mathrm{CP}$ ). CP and the adhesives were air-dried with normal air $\left(23 \pm 1^{\circ} \mathrm{C}\right)$ or warm air $\left(60 \pm 5^{\circ} \mathrm{C}\right)$, light-cured, and the cavities were filled with a flowable composite. Interfacial gap formation was evaluated using swept-source optical coherence tomography immediately after filling, after 24 h, 5000 and 10,000 thermal cycles, and an additional 1 year of water storage. Results: Without the silane pretreatment, all specimens soon detached from the cavities. Warm air-drying significantly decreased gap formation compared to normal air-dried groups $(p<0.001)$ and improved long-term stability $(p<0.001)$. The lowest gap formation was observed with UBQ when the silane pretreatment was combined with warm air-drying. Conclusions: Composite adaptation to LDS was insufficient without silanization, but it was stable in the long term if the silane pretreatment and warm air-drying were combined.
\end{abstract}

Keywords: ceramic; repair; durability; silane; optical coherence tomography; gap formation

\section{Introduction}

Dental ceramics have been praised for their excellent aesthetic properties, and their manufacturing has recently been simplified by novel technologies such as computerassisted design and computer-assisted manufacturing (CAD-CAM) [1]. On the other hand, one of the principal disadvantages of ceramics is that they are susceptible to brittle fracture, clinically resulting in partial or complete restoration failure. The replacement of the whole restoration is expensive and time-consuming, so a repair is preferable as it is less invasive and costs less [2]. However, hydrofluoric acid (HF) etching, which is used to increase the surface roughness of glass-ceramic restorations prior to cementation $[3,4]$, should not be used for intraoral procedures because of the toxicity of HF. Therefore, achieving stable adhesion remains a persistent issue in the repair of glass-ceramic restorations.

Silanes have been used to promote adhesion to silica-based materials, including glass ceramics. Firstly, their application reduces surface tension and facilitates the wetting of the substrate [1]. Secondly, dental silanes are bifunctional molecules with alkoxy 
groups and methacrylate groups that can form covalent bonds with the ceramic surface and resins, respectively [4-6]. The mechanism involves the hydrolysis of alkoxy groups in acidic $\mathrm{pH}$ followed by their condensation into siloxanes, while the methacrylate groups polymerize with resin monomers. Most silane coupling agents consist of $\gamma$-methacryloxypropyltrimethoxysilane ( $\gamma$-MPTS), ethanol, water, and an organic acid or an acidic monomer to adjust the $\mathrm{pH}$ and activate the silane. In one-bottle silane coupling agents, long-term storage led to an excessive pre-hydrolysis of $\gamma$-MPTS and its self-condensation into inactive siloxane oligomers [6]. Therefore, some contemporary one-bottle silane coupling agents are water-free to prevent the premature hydrolysis of the silane. It is thought that they utilize the ambient humidity of air and/or the substrate to activate the silane after application [6].

Recently, the push for the simplification of bonding procedures led to the introduction of 10-MDP-based universal adhesives which can bond to various substrates. In order to promote their adhesion to silica-based materials, some universal adhesives also contain $\gamma$-MPTS. However, several studies reported that their bond strengths to glass ceramics were low [7-12], resulting from the premature hydrolysis of $\gamma$-MPTS and the formation of oligomers due to the presence of water and their $\mathrm{pH}$ of $\sim 1.5-3$ [13]. This mechanism was proved using various methods, including Fourier transform infrared spectroscopy (FTIR), Raman spectroscopy, nuclear magnetic resonance (NMR), and X-ray photoelectric spectroscopy (XPS) [8-11]. Numerous studies reported that the bond strength of universal adhesives to glass ceramics improved significantly after a pretreatment with a silane coupling agent $[8-12,14,15]$. Nevertheless, the bond strength decreased after thermal cycling or water storage $[9-12,15]$, possibly due to residual solvents in the adhesive layers. We therefore hypothesize that warm air-drying could enhance the durability by facilitating solvent evaporation $[16,17]$. In addition, the hydrolysis of silanes is dependent on temperature [6], so warm air could also contribute to the activation of the silane and thus improve the bonding performance [18-21].

The purpose of this study was to investigate the effects of a silane pretreatment and warm air-drying on the adaptation of a silane-containing universal adhesive to lithium disilicate ceramics (LDS) using swept-source optical coherence tomography (SS-OCT). SS-OCT is a non-destructive imaging method that has been used in dental research to assess gap formation at adhesive interfaces under clinically representative conditions and to detect defects in restorations and hard dental tissues [22,23]. In this study, it was used to analyze the development of gap formation at the ceramic-composite interface shortly after polymerization, thermal cycling, and an additional 1 year of water storage. The performance of the universal adhesive was compared with a solvent-free bonding agent of a two-step self-etch adhesive system. The null hypotheses were that there would be no significant difference in gap formation between (1) groups with or without a silane pretreatment, and (2) groups dried with normal or warm air.

\section{Materials and Methods}

Forty tapered cavities ( $2 \mathrm{~mm}$ bottom diameter, $4 \mathrm{~mm}$ upper diameter, $3 \mathrm{~mm}$ depth) prefabricated in LDS blocks (IPS e.max CAD; Ivoclar Vivadent, Schaan, Liechtenstein) were used in this study. The cavity design was selected instead of flat surfaces to increase the ratio of bonded to unbonded surfaces, also known as the configuration factor (C-factor), and thus increase the stress to the interface induced by composite shrinkage and thermal cycling. The materials included a silane-containing universal adhesive (Clearfil Universal Bond Quick ER; UBQ; Kuraray Noritake Dental, Tokyo, Japan), a bonding agent of a twostep self-etch adhesive system (Clearfil SE Bond 2; SE2; Kuraray Noritake Dental), a silane coupling agent (Clearfil Ceramic Primer; CP; Kuraray Noritake Dental), and a flowable resin composite (Estelite Flow Quick; EFQ; Tokuyama Dental, Tokyo, Japan). An overview of their composition is presented in Table 1. 
Table 1. An overview of materials used in this study.

\begin{tabular}{|c|c|c|}
\hline Material (Batch Number) & Manufacturer & Composition \\
\hline IPS e.max CAD & $\begin{array}{l}\text { Ivoclar Vivadent, } \\
\text { Schaan, Liechtenstein }\end{array}$ & $\mathrm{SiO}_{2}, \mathrm{Li}_{2} \mathrm{O}, \mathrm{K}_{2} \mathrm{O}, \mathrm{P}_{2} \mathrm{O}_{5}, \mathrm{ZrO}_{2}, \mathrm{ZnO}$, other oxides, pigments \\
\hline $\begin{array}{c}\text { Clearfil Ceramic Primer } \\
\text { (A50030) }\end{array}$ & $\begin{array}{l}\text { Kuraray Noritake } \\
\text { Dental, Tokyo, Japan }\end{array}$ & Ethanol, $\gamma$-MPTS, 10-MDP \\
\hline $\begin{array}{l}\text { Clearfil Universal Bond } \\
\text { Quick ER (4C0008) }\end{array}$ & $\begin{array}{l}\text { Kuraray Noritake } \\
\text { Dental, Tokyo, Japan }\end{array}$ & $\begin{array}{l}\text { 10-MDP, Bis-GMA, HEMA, hydrophilic aliphatic dimethacrylate, } \\
\text { colloidal silica, silane coupling agent, sodium fluoride, CQ, } \\
\text { ethanol, water }\end{array}$ \\
\hline Clearfil SE Bond 2 (1K0127) & $\begin{array}{l}\text { Kuraray Noritake } \\
\text { Dental, Tokyo, Japan }\end{array}$ & $\begin{array}{l}\text { Bond: 10-MDP, Bis-GMA, HEMA, hydrophobic aliphatic } \\
\text { dimethacrylate, silanated colloidal silica, CQ, initiators, accelerators }\end{array}$ \\
\hline Estelite Flow Quick (040026) & $\begin{array}{l}\text { Tokuyama Dental, } \\
\text { Tokyo, Japan }\end{array}$ & $\begin{array}{c}\text { Bis-MPEPP, TEGDMA, UDMA, silica-zirconia filler (53 vol. } \%, 0.4 \mu \mathrm{m} \\
\text { and } 0.07 \mu \mathrm{m} \text { ), CQ }\end{array}$ \\
\hline
\end{tabular}

Abbreviations: $\gamma$-MPTS: $\gamma$-methacryloxypropyltrimethoxysilane; 10-MDP: 10-methacryloyloxydecyl dihydrogen phosphate; HEMA: 2-hydroxyethyl methacrylate; Bis-GMA: bisphenol A glycidyl methacrylate; CQ: camphorquinone; Bis-MPEPP: bisphenol A polyethoxy dimethacrylate; TEGDMA: triethylene glycol dimethacrylate; UDMA: urethane dimethacrylate.

All 40 cavities were cleaned with ethanol, ultrasonically cleaned for $10 \mathrm{~min}$ in distilled water, and air-dried. Then, the cavities were randomly assigned to 8 experimental groups $(n=5)$ according to the adhesive (UBQ or SE2), the application of $C P$, and the air-drying procedure which was performed either using normal air $\left(23 \pm 1{ }^{\circ} \mathrm{C} ; \mathrm{N}\right)$ or warm air $\left(60 \pm 5^{\circ} \mathrm{C} ; \mathrm{W}\right)$. The experimental groups were as follows: (1) UBQ(N)—normal air-dried UBQ without $C P$; (2) UBQ(W) - warm air-dried UBQ without $C P$; (3) $C P(N) U B Q(N)$ normal air-dried UBQ pretreated with normal air-dried CP; (4) $\mathrm{CP}(\mathrm{N}) \mathrm{UBQ}(\mathrm{W})$-warm airdried UBQ pretreated with normal air-dried CP; (5) CP(W)UBQ(N) - normal air-dried UBQ pretreated with warm air-dried $\mathrm{CP} ;(6) \mathrm{CP}(\mathrm{W}) \mathrm{UBQ}(\mathrm{W})$-warm air-dried UBQ pretreated with warm air-dried CP; (7) CP(N)SE2(N) — normal air-dried SE2 pretreated with normal air-dried CP; and (8) $\mathrm{CP}(\mathrm{W}) \mathrm{SE2}(\mathrm{N})$ - normal air-dried SE2 pretreated with warm air-dried $\mathrm{CP}$. The overview of experimental groups is presented in Figure 1. SE2 was only used with the $\mathrm{CP}$ pretreatment, because it does not contain any silane, and it was air-blown using only normal air, because it does not contain solvents.

$\mathrm{CP}$ was applied with a microbrush and agitated for $20 \mathrm{~s}$ prior to air-drying. The adhesives were applied with a disposable microbrush without agitation and air-dried as well. Air-drying was performed for $20 \mathrm{~s}$ either with normal air using a dental air syringe from a distance of $1 \mathrm{~cm}$, or warm air using a heat blower (Dyson Supersonic Dryer, Dyson, Malmesbury, UK) from a distance of $5 \mathrm{~cm}$. The distance between specimens and the heat blower was increased to obtain a similar air-pressure in both air-drying approaches and because the temperature near the heat blower's orifice was almost $100{ }^{\circ} \mathrm{C}$. During air-drying, the air temperature near the surface of the LDS blocks was checked using a thermocouple. After the adhesives were air-dried, they were light-cured for $10 \mathrm{~s}$ using a LED light-curing unit (Elipar DeepCure-L; $1470 \mathrm{~mW} / \mathrm{cm}^{2} ; 3 \mathrm{M}$, St. Paul, MN, USA), and cavities were filled with EFQ in three $1 \mathrm{~mm}$ increments, each light-cured for $20 \mathrm{~s}$. Then, specimens were incubated in distilled water for $24 \mathrm{~h}$ at $37^{\circ} \mathrm{C}$ and subsequently subjected to 10,000 thermal cycles (TC) between $5{ }^{\circ} \mathrm{C}$ and $55^{\circ} \mathrm{C}$ (dwell time $30 \mathrm{~s}$, transfer time $2 \mathrm{~s}$ ). An additional 1 year of water storage at $37^{\circ} \mathrm{C}$ followed for specimens that did not detach from cavities during thermocycling. Specimens that detached from cavities were not submitted to further aging procedures, and they were assigned $100 \%$ gap formation.

Gap formation was observed using an SS-OCT device (IVS-2000; Santec, Tokyo, Japan) immediately after filling, after $24 \mathrm{~h}$ of water storage, $5000 \mathrm{TC}, 10,000 \mathrm{TC}$, and the additional 1 year of water storage. The device was equipped with a laser light source (bandwidth $110 \mathrm{~nm}$, center wavelength $1330 \mathrm{~nm}$, sweep rate $30 \mathrm{kHz}$ ) that scanned the area of interest $\left(5 \times 5 \mathrm{~mm}^{2}\right)$ in $\mathrm{X}$ and $\mathrm{Z}$ dimensions. Scans were performed in 6 planes by rotating the laser beam $0^{\circ}, 30^{\circ}, 60^{\circ}, 90^{\circ}, 120^{\circ}$, and $150^{\circ}$. Light backscattered from specimens was collected by the system, digitized in time scale, and analyzed in a Fourier domain to create depth-resolved reflectivity profiles (A-scans) at each point. Raw data files (B-scans) were 


\section{Materials}

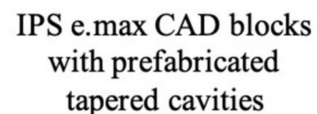

Clearfil Ceramic Primer (CP)

Clearfil Universal Bond Quick ER (UBQ)

Clearfil SE Bond 2 (SE2)

obtained by combining the A-scans from each plane, and they were also converted to 2-dimensional cross-sectional gray-scale images of $2000 \times 1000 \mathrm{px}$ resolution [22,23]. As a result of differences in refractive indices, gaps significantly increase the signal intensity and appear as bright spots in the images.

\section{Experimental groups}

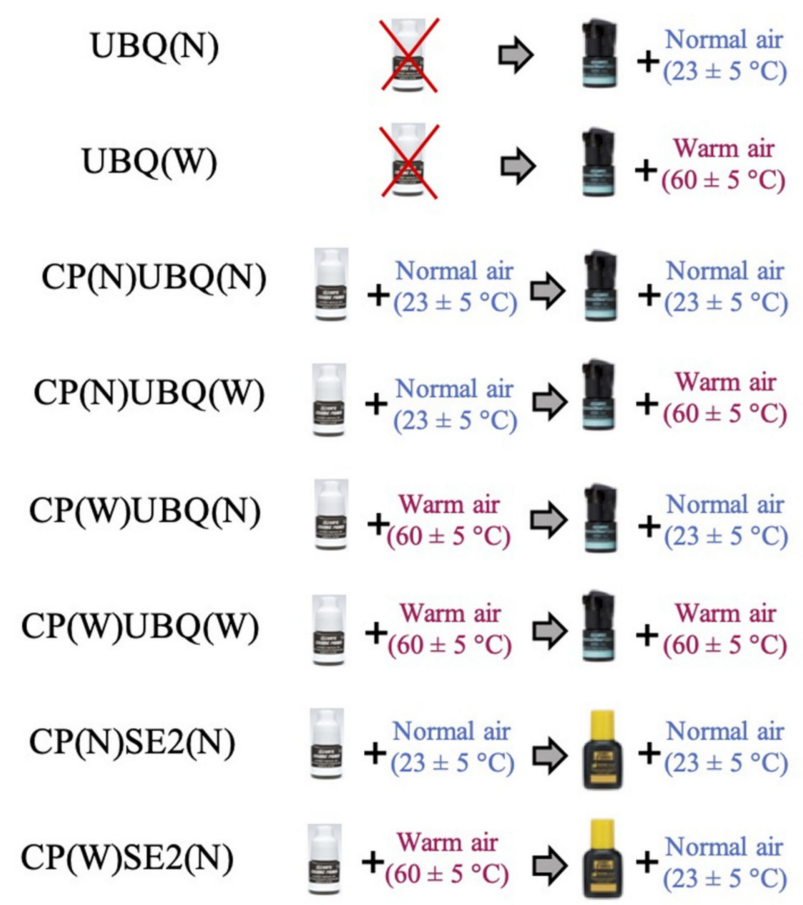

\section{Aging procedures}

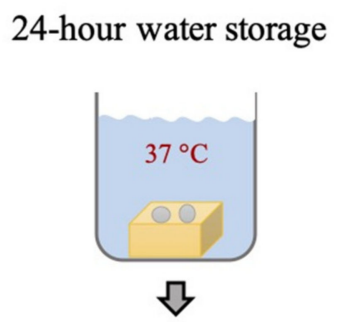

10,000 thermal cycles

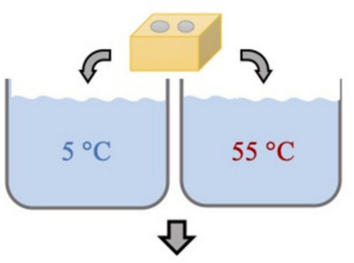

1-year water storage

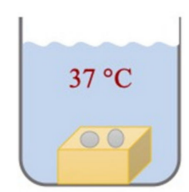

Figure 1. Overview of experimental groups and aging procedures. Abbreviations: CP: Clearfil Ceramic Primer, UBQ: Clearfil Universal Bond Quick ER, SE2: Clearfil SE Bond 2, N: normal air-drying, W: warm air-drying.

The ImageJ software (version 1.48 v, National Institutes of Health, Bethesda, Maryland, USA) was used to measure the gap length. B-scans were imported to the software, a size scale was set, and a median filter was applied to reduce the noise. The area of the interface was then selected and binarized using an auto-threshold function of the software to detect pixels with significantly higher brightness compared to the background. The total length of bright clusters was automatically calculated using an ImageJ plugin, divided by the length of the interface, and multiplied by 100 to obtain relative gap length in percentages [22,23]. The analyses were performed separately for the cavity bottom and lateral walls.

The Shapiro-Wilk test indicated that the distribution of gap length data was not normal. Therefore, a non-parametric Kruskal-Wallis test was used to analyze the effect of bonding procedures and aging conditions, followed by multiple comparisons using the Steel-Dwass method. All analyses were performed at $\alpha=0.05$ (JMP 13.2.1 for Windows, SAS Institute, Cary, NC, USA). In some groups, all specimens detached from cavities, resulting in $100 \%$ gap formation and no standard deviation. These groups had to be eliminated from the analyses and were considered significantly different from another group if the upper confidence bound of the other group did not reach $100 \%$.

\section{Results}

The rates of interfacial gap formation at the cavity bottom and lateral walls are presented in Tables 2 and 3. Representative SS-OCT images are shown in Figure 2. 
Table 2. Gap formation at the cavity bottom in percentages (mean $\pm \mathrm{SD}$ ).

\begin{tabular}{|c|c|c|c|c|c|}
\hline Group & Immediate & $24 \mathrm{~h}$ & 5000 TC & 10,000 TC & 1 Year \\
\hline UBQ(N) & $84.0 \pm 4.2 \mathrm{Aa}$ & $100.0 \pm 0.0^{\mathrm{Ba}}$ & $100.0 \pm 0.0^{\mathrm{Ba}}$ & $100.0 \pm 0.0^{\mathrm{Ba}}$ & $100.0 \pm 0.0^{\mathrm{Ba}}$ \\
\hline UBQ(W) & $79.2 \pm 3.3^{\mathrm{Ab}}$ & $82.8 \pm 3.1^{\mathrm{Bb}}$ & $100.0 \pm 0.0^{\mathrm{Ca}}$ & $100.0 \pm 0.0^{\mathrm{Ca}}$ & $100.0 \pm 0.0^{\mathrm{Ca}}$ \\
\hline CP(N)UBQ(N) & $11.7 \pm 2.2^{\mathrm{Ac}}$ & $14.6 \pm 1.8^{\mathrm{Bc}}$ & $80.8 \pm 3.0^{\mathrm{Cb}}$ & $82.6 \pm 4.1^{\mathrm{Cb}}$ & $100.0 \pm 0.0^{\mathrm{Da}}$ \\
\hline CP(N)UBQ $(W)$ & $5.0 \pm 0.8^{\mathrm{Ad}}$ & $5.1 \pm 0.8^{\mathrm{Ad}}$ & $9.3 \pm 2.5^{\mathrm{Be}}$ & $10.6 \pm 3.8^{\mathrm{Be}}$ & $25.3 \pm 1.5^{\mathrm{Cc}}$ \\
\hline CP(W)UBQ(N) & $5.2 \pm 1.0 \mathrm{Ad}$ & $5.6 \pm 0.9 \mathrm{Ad}$ & $8.8 \pm 2.6^{\mathrm{Be}}$ & $10.0 \pm 1.3^{\mathrm{Be}}$ & $16.6 \pm 1.3^{\mathrm{Cd}}$ \\
\hline CP(W)UBQ(W) & $4.8 \pm 0.6^{\mathrm{Ad}}$ & $4.9 \pm 0.5^{\mathrm{Ad}}$ & $8.4 \pm 1.3^{\mathrm{Be}}$ & $10.0 \pm 1.8^{\mathrm{Ce}}$ & $18.3 \pm 1.8^{\mathrm{Dd}}$ \\
\hline CP(N)SE2(N) & $4.4 \pm 1.9$ Ade & $4.5 \pm 1.0 \mathrm{Ae}$ & $42.8 \pm 3.7^{\mathrm{Bc}}$ & $52.0 \pm 4.6^{\mathrm{BCc}}$ & $96.6 \pm 6.9 \mathrm{Dab}$ \\
\hline CP(W)SE2(N) & $3.7 \pm 1.3^{\mathrm{Ae}}$ & $4.8 \pm 2.6^{\text {Ade }}$ & $19.7 \pm 3.8^{\mathrm{Bd}}$ & $32.8 \pm 3.5^{\mathrm{Cd}}$ & $90.0 \pm 8.5^{\mathrm{Db}}$ \\
\hline
\end{tabular}

Different superscript letters indicate significant differences $(\mathrm{p}<0.05)$ between groups: uppercase letters in rows, lowercase letters in columns. Please refer to Materials and Methods (second paragraph) for the description of bonding procedures in each group.

Table 3. Gap formation at the cavity lateral walls in percentages (mean $\pm \mathrm{SD}$ ).

\begin{tabular}{|c|c|c|c|c|c|}
\hline Group & Immediate & $24 \mathrm{~h}$ & 5000 TC & $10,000 \mathrm{TC}$ & 1 year \\
\hline UBQ(N) & $24.8 \pm 2.6^{\mathrm{Aa}}$ & $100.0 \pm 0.0^{\mathrm{Ba}}$ & $100.0+0.0^{\mathrm{Ba}}$ & $100.0 \pm 0.0^{\mathrm{Ba}}$ & $100.0 \pm 0.0^{\mathrm{Ba}}$ \\
\hline UBQ(W) & $27.4 \pm 4.7^{\mathrm{Aa}}$ & $28.8 \pm 4.1^{\mathrm{Ab}}$ & $100.0+0.0^{\mathrm{Ba}}$ & $100.0 \pm 0.0^{\mathrm{Ba}}$ & $100.0 \pm 0.0^{\mathrm{Ba}}$ \\
\hline CP(N)UBQ(N) & $15.9 \pm 1.3^{\mathrm{Ab}}$ & $14.9 \pm 1.7 \mathrm{Ad}$ & $17.6+1.5^{\mathrm{Bb}}$ & $19.2 \pm 1.0^{\mathrm{Cc}}$ & $100.0 \pm 0.0 \mathrm{Da}$ \\
\hline $\mathrm{CP}(\mathrm{N}) \mathrm{UBQ}(\mathrm{W})$ & $14.2 \pm 1.2^{\mathrm{Ac}}$ & $18.2 \pm 0.8^{\mathrm{Bc}}$ & $18.3+1.1^{\mathrm{Bbc}}$ & $19.2 \pm 1.4^{\mathrm{Cc}}$ & $21.4 \pm 1.0^{\mathrm{Dc}}$ \\
\hline CP(W)UBQ(N) & $11.8 \pm 1.2^{\mathrm{Ad}}$ & $12.7 \pm 1.0^{\mathrm{Be}}$ & $14.3+1.9^{\mathrm{Cd}}$ & $16.1 \pm 1.5^{\mathrm{CDd}}$ & $18.3 \pm 1.0^{\mathrm{Ed}}$ \\
\hline CP(W)UBQ(W) & $12.7 \pm 0.8^{\mathrm{Ad}}$ & $12.9 \pm 1.2^{\mathrm{Ae}}$ & $14.2+1.8^{\mathrm{Bd}}$ & $15.6 \pm 1.8^{\mathrm{Cd}}$ & $18.1 \pm 0.8^{\mathrm{Dd}}$ \\
\hline CP(N)SE2(N) & $15.6 \pm 1.0 \mathrm{Abc}$ & $17.3 \pm 0.8^{\mathrm{Bc}}$ & $19.0+1.2^{\mathrm{Cc}}$ & $19.9 \pm 1.2 \mathrm{Cbc}$ & $86.5 \pm 27.5^{\mathrm{Da}}$ \\
\hline CP(W)SE2(N) & $16.3 \pm 1.1^{\mathrm{Ab}}$ & $18.0 \pm 1.3^{\mathrm{Bc}}$ & $18.6+2.4 \mathrm{Bbc}$ & $20.6 \pm 1.7^{\mathrm{Cb}}$ & $56.3 \pm 36.3^{\mathrm{Db}}$ \\
\hline
\end{tabular}

Different superscript letters indicate significant differences $(\mathrm{p}<0.05)$ between groups: uppercase letters in rows, lowercase letters in columns. Please refer to Materials and Methods (second paragraph) for the description of bonding procedures in each group.

Groups bonded with UBQ without CP pretreatment exhibited the highest gap formation. Moreover, all specimens of UBQ(N) detached from the cavities within $24 \mathrm{~h}$, and specimens of $\mathrm{UBQ}(\mathrm{W})$ detached during thermocycling. The application of $\mathrm{CP}$ prior to UBQ improved the adaptation significantly $(\mathrm{p}<0.001)$. However, in the case of $\mathrm{CP}(\mathrm{N}) \mathrm{UBQ}(\mathrm{N})$, gap formation at the cavity bottom increased substantially after 5000 TC $(\mathrm{p}<0.001)$, and all five specimens dislocated from the cavities during the additional 1 year of water storage. The groups where $\mathrm{CP}$ and/or UBQ were dried with warm air exhibited significantly lower gap formation than $\mathrm{CP}(\mathrm{N}) \mathrm{UBQ}(\mathrm{N})(\mathrm{p}<0.001)$. The adaptation was also more stable: all specimens withstood thermocycling and the additional 1 year of water storage. The adaptation of $\mathrm{CP}(\mathrm{W}) \mathrm{UBQ}(\mathrm{W})$ and $\mathrm{CP}(\mathrm{W}) \mathrm{UBQ}(\mathrm{N})$ was similar to that of $\mathrm{CP}(\mathrm{N}) \mathrm{UBQ}(\mathrm{W})$ at the cavity bottom $(\mathrm{p}>0.5)$ except for the 1 year of water storage, which resulted in a significantly higher gap formation in the $\mathrm{CP}(\mathrm{N}) \mathrm{UBQ}(\mathrm{W})$ group $(\mathrm{p}<0.001)$. At the lateral walls, $C P(W) U B Q(W)$ and $C P(W) U B Q(N)$ exhibited significantly lower gap formation than $\mathrm{CP}(\mathrm{N}) \mathrm{UBQ}(\mathrm{W})$ in all assessments $(\mathrm{p}<0.001)$.

$\mathrm{CP}(\mathrm{N}) \mathrm{SE} 2(\mathrm{~N})$ exhibited a significantly lower gap formation than $\mathrm{CP}(\mathrm{N}) \mathrm{UBQ}(\mathrm{N})$ at the cavity bottom $(p<0.001)$ except for the 1 year of water storage which resulted in the dislocation of four specimens and thus similar gap formation in these groups $(p=0.178)$. At the lateral walls, the gap formation of $\mathrm{CP}(\mathrm{N}) \mathrm{SE} 2(\mathrm{~N})$ was significantly higher than that of $\mathrm{CP}(\mathrm{N}) \mathrm{UBQ}(\mathrm{N})$ after $24 \mathrm{~h}$ and $5000 \mathrm{TC}(\mathrm{p}<0.05)$, but there was no significant difference between them in the rest of the observations $(p>0.05)$. Warm air-drying did not have a significant effect on the immediate and 24-h gap formation ( $p>0.05)$, but $C P(W) S E 2(N)$ exhibited significantly lower gap formation than $\mathrm{CP}(\mathrm{N}) \mathrm{SE} 2(\mathrm{~N})$ after thermocycling at the cavity bottom $(p<0.001)$. The additional 1 year of water storage led to the detachment of four $\mathrm{CP}(\mathrm{N}) \mathrm{SE} 2(\mathrm{~N})$ specimens and two $\mathrm{CP}(\mathrm{W}) \mathrm{SE} 2(\mathrm{~N})$ specimens, resulting in a significant increase in gap formation compared to values after thermocycling $(\mathrm{p}<0.001)$. The 1-year gap formation of $C P(W) S E 2(N)$ was significantly lower than that of $C P(N) S E 2(N)$ at the lateral walls $(p=0.0025)$ but not at the cavity bottom $(p=0.07)$. Compared to the warm 
air-dried groups of UBQ with $\mathrm{CP}$ pretreatment, the 1-year gap formation of $\mathrm{CP}(\mathrm{W}) \mathrm{SE} 2(\mathrm{~N})$ was significantly higher $(\mathrm{p}<0.001)$.
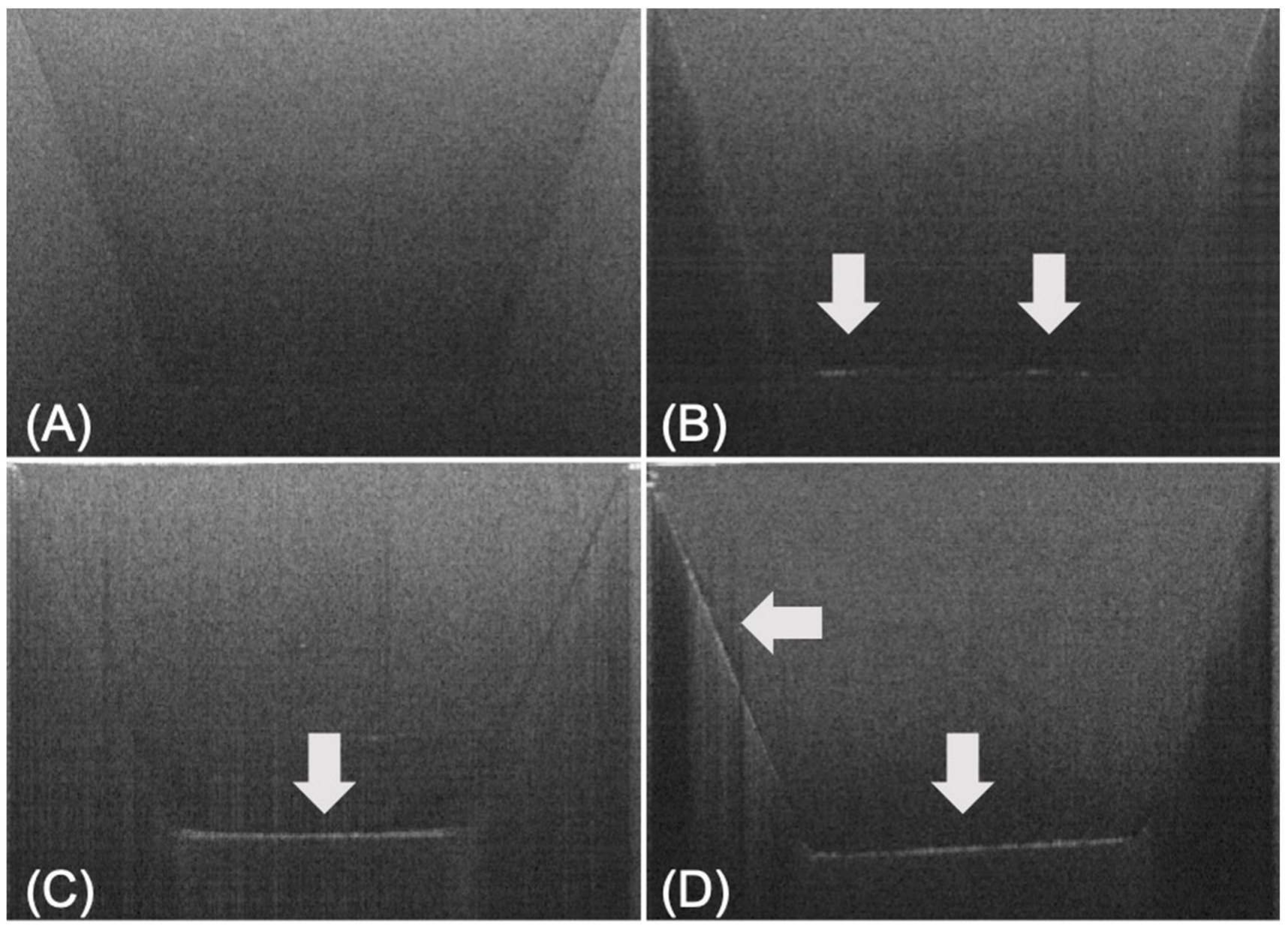

Figure 2. Representative swept-source optical coherence tomography (SS-OCT) images with a varying degrees of interfacial gap formation. Gap formation appears as bright spots and is highlighted by the white arrows. (A) Almost no gap formation, typical for immediate and 24-h observations of groups with CP pretreatment. (B) Minor gap formation at the cavity bottom, characteristic for warm air-dried groups of $C P+U B Q$ after the 1 year of water storage. (C) Extensive gap formation at the cavity bottom, representative of UBQ groups without $C P$ and thermocycled specimens of $C P(N) U B Q(N)$. (D) Extensive gap formation at the cavity bottom and lateral walls, observed in specimens shortly before detachment from cavities.

\section{Discussion}

The repair of fractured glass-ceramic restorations is preferable to their complete replacement, but it is difficult to achieve a stable bond between the ceramic and resin composite, because HF etching should not be used intraorally. Therefore, the application of silane coupling agents has been recommended to promote chemical adhesion to glass ceramics. To simplify the bonding procedure, silanes have been incorporated in some recent universal adhesives, but it was revealed that their bonding to glass ceramics was low [7-12]. This study examined whether the application of a silane coupling agent $(\mathrm{CP})$ and warm air-drying could improve composite adaptation to LDS blocks. The results showed that interfacial gap formation decreased significantly when CP was applied prior to UBQ, so the first null hypothesis was rejected. It was also revealed that warm air-drying resulted in a significantly better composite adaptation to LDS compared to normal air-drying, so the second hypothesis was rejected as well.

With normal air-drying, UBQ exhibited a high rate of gap formation and the specimens dislocated from cavities within $24 \mathrm{~h}$, indicating an insufficient adhesion to the LDS blocks. 
This can be attributed to the absence of HF etching, resulting in the lack of micromechanical bonding, and the premature hydrolysis of the incorporated silane, leading to its selfcondensation into inactive oligomers [8-11] and thus poor chemical bonding. Previous studies reported low bond strengths of silane-containing universal adhesives to glass ceramics [7-12], but debonding was not commonly observed. Compared to bond strength testing where flat surfaces are used, the C-factor of the cavities in this study was higher which could increase the shrinkage stress of the flowable composite and contribute to the detachment of specimens with a weak bond.

This result confirmed that a silane pretreatment is necessary to improve the adhesion of universal adhesives to glass ceramics. Previous studies revealed a significant increase in bond strength if a silane coupling agent was used prior to the application of universal adhesives [8-12,14,15]. In this study, gap formation decreased significantly when CP was applied before UBQ and even lower gap formation was observed with SE2. The difference between normal air-dried groups of UBQ and SE2 with CP pretreatment was presumably caused by the presence of water and volatile solvents in UBQ. Their evaporation was shown to be incomplete even when air-drying was extended to $20 \mathrm{~s}[16,17]$, and the residual solvent may impair the polymerization of adhesives [24,25], thus increasing the interfacial gap formation.

Additionally, the application of CP improved the sealing stability. Although gap formation at the cavity bottom increased significantly compared to 24-h values with both UBQ and SE2, all CP-pretreated specimens endured thermocycling. We suppose that this was mainly due to the mechanical stress induced by different thermal expansion coefficients of LDS and the resin composite. With the intention to enlarge the stress, tapered cavities were used in this study instead of flat surfaces, because they have a higher C-factor. The stability of the bond was further challenged by the subsequent 1 year of water storage, which resulted in the detachment of all five specimens in the case of normal air-dried UBQ pretreated with normal air-dried CP and four specimens if SE2 was used. The presence of hydrophilic monomers-2-hydroxyethyl methacrylate in both adhesives [26] and a methacrylamide monomer in UBQ [27]—and remnants of solvents in UBQ probably facilitated water sorption into the adhesive layers [24], which led to the hydrolytic degradation of the chemical bond with LDS.

Silane coupling agents are activated by hydrolysis in acidic conditions and the application of heat can increase the hydrolysis reaction rate [6]. Therefore, the effect of warm air-drying was examined, because it could promote chemical bonding to glass ceramics. A previous study reported that drying of $\gamma$-MPTS with hot air $\left(100{ }^{\circ} \mathrm{C}\right)$ for 1 min significantly increased the micro-tensile bond strength of resin composite to leucite reinforced glass ceramics [18]. Another study examined the effect of heat treatment of CP in an oven $\left(100{ }^{\circ} \mathrm{C}\right)$ for $2 \mathrm{~min}$ or using warm air $\left(50^{\circ} \mathrm{C}\right)$ for $1 \mathrm{~min}$ and revealed that both methods were effective in increasing the bond strength of a resin cement to glass ceramics [20]. The former study showed that the heat treatment even outperformed HF etching combined with normal air-dried silane [18], while the latter showed no significant difference between them [20]. A significant improvement in bond strength was also reported after warm air-treatment $\left(45 \pm 5^{\circ} \mathrm{C}\right)$ of a silane coupling agent for $2 \mathrm{~min}$, but the bond strength was still significantly lower compared to that of HF etching [19].

In this study, a heat blower was used to produce warm air. Near its orifice, the airtemperature was almost $100{ }^{\circ} \mathrm{C}$ and the airstream was strong, so the distance between specimens and the heat blower was set to $5 \mathrm{~cm}$ to obtain a temperature of $60 \pm 5^{\circ} \mathrm{C}$ and air-pressure comparable to normal air-drying using the dental syringe. Warm air-drying did not strongly affect the immediate gap formation of UBQ, presumably because only a few unhydrolyzed silane molecules were remaining. However, as opposed to UBQ dried with normal air, the warm air-dried specimens withstood the 24 -h water storage. This could be due to an increase in the kinetic energy of molecules after heat treatment, which would facilitate water and solvent evaporation and positively affect polymerization [16,17]. Consequently, the adhesive layer would be less prone to water sorption and hydrolytic 
degradation of the bond. Nevertheless, all five specimens of warm air-dried UBQ detached from cavities during thermocycling, probably due to the fact that the incorporated silane was pre-hydrolyzed.

In groups where $\mathrm{CP}$ was applied prior to $\mathrm{UBQ}$, warm air-drying significantly decreased gap formation compared to UBQ pretreated with normal air-dried CP. This could be due to improved silane activation and/or the positive effect of heat treatment on UBQ. There was no significant difference between groups with warm air-dried $\mathrm{CP}$ irrespective of air temperature used to air-dry UBQ, but warm air-dried UBQ pretreated with normal air-dried CP exhibited a slightly higher gap formation at the lateral walls under all storage conditions and at the cavity bottom after 1 year of water storage. These results indicated that direct warm air-treatment of $\mathrm{CP}$ was important for the stability of the chemical bond between UBQ and LDS. It was surprising that the performance of normal air-dried UBQ pretreated warm air-dried CP was not affected by remnants of solvents in UBQ, but the ceramic surface remained warm after the warm air-treatment of $\mathrm{CP}$, so we speculate that this contributed to solvent evaporation from UBQ even when normal air-drying was used. All specimens pretreated with $\mathrm{CP}$ and bonded with UBQ that received warm air-drying withstood thermocycling and the additional 1 year of water storage.

Warm air-drying of CP significantly improved the adaptation of SE2 as well. Compared to the SE2 group pretreated with normal air-dried $\mathrm{CP}$, warm air-drying of $\mathrm{CP}$ resulted in a significantly lower gap formation at the cavity bottom after thermocycling. The additional 1 year of water storage increased the gap formation even in the warm air-dried SE2 group and two specimens detached from the cavities, but the adaptation at the lateral walls was still significantly better than if $\mathrm{CP}$ had received normal air-drying. However, it is noteworthy that after thermocycling and the 1 year of water storage, the gap formation of SE2 pretreated with warm air-dried $\mathrm{CP}$ was significantly higher than that of the $\mathrm{CP}$-pretreated groups bonded with $\mathrm{UBQ}$, in which either $\mathrm{CP}$ or UBQ received warm air-drying. We speculate that this could be related to the presence of water in UBQ and its higher acidity $(\mathrm{pH}=2.3)$ compared to the bonding agent of SE2. As CP is a water-free silane coupling agent, water from UBQ and its acidic $\mathrm{pH}$ could contribute to the hydrolysis of $\mathrm{CP}$ [6] even after it was activated with warm air and thus improve the chemical bond with LDS.

The results revealed that the activation of $\mathrm{CP}$ by warm air-drying is very effective, especially when combined with the universal adhesive UBQ. Therefore, this procedure could be useful in the repair of ceramic restorations. However, heat blowers cannot be used clinically, because their nozzle is very wide, and the high air temperature might burn the soft tissues. For clinical usage, it would be necessary to use a warm air-drying device that could be connected to the dental syringe, in order to ensure a controlled application of the heat, as proposed by Yonekura et al. [17].

Author Contributions: Conceptualization, M.N. and K.H.; methodology, Y.S. and J.T.; formal analysis, A.A. and A.T.; investigation, P.P.K.K.; resources, Y.S. and J.T.; writing-original draft preparation, P.P.K.K. and A.T.; writing-review and editing, A.A., K.H., J.T., M.N.; visualization, P.P.K.K. and A.T.; supervision, M.N.; project administration, A.T.; funding acquisition, K.H., Y.S., J.T., M.N. All authors have read and agreed to the published version of the manuscript.

Funding: This research and the APC was funded by the Ministry of Education, Culture, Sports, Science and Technology of Japan, grant numbers 18K09571 and 19K10106.

Institutional Review Board Statement: Not applicable.

Informed Consent Statement: Not applicable.

Data Availability Statement: Data available on request.

Conflicts of Interest: The authors declare no conflict of interest.

\section{References}

1. Silva, L.H.D.; Lima, E.; Miranda, R.B.P.; Favero, S.S.; Lohbauer, U.; Cesar, P.F. Dental ceramics: A review of new materials and processing methods. Braz. Oral Res. 2017, 31, 133-146. [CrossRef] [PubMed] 
2. Neis, C.A.; Albuquerque, N.L.G.; Albuquerque, I.S.; Gomes, E.A.; Souza-Filho, C.B.; Feitosa, V.P.; Spazzin, A.O.; Bacchi, A. Surface treatments for repair of feldspathic, leucite- and lithium disilicate-reinforced glass ceramics using composite resin. Braz. Oral J. 2015, 26, 152-155. [CrossRef] [PubMed]

3. Addison, O.; Marquis, P.M.; Fleming, G.J.P. The impact of hydrofluoric acid surface treatments on the performance of a porcelain laminate restorative material. Dent. Mater. 2007, 23, 461-468. [CrossRef] [PubMed]

4. Ho, G.W.; Matinlinna, J.P. Insights on ceramics as dental materials. Part II: Chemical surface treatments. Silicon 2011, 3, 117-123. [CrossRef]

5. Bona, A.D.; Shen, C.; Anusavice, K.J. Work of adhesion of resin on treated lithia disilicate-based ceramic. Dent. Mater. 2004, 20 , 338-344. [CrossRef]

6. Matinlinna, J.P.; Lung, C.Y.K.; Tsoi, J.K.H. Silane adhesion mechanism in dental applications and surface treatments: A review. Dent. Mater. 2018, 34, 13-28. [CrossRef] [PubMed]

7. Noda, Y.; Nakajima, M.; Takahashi, M.; Mamanee, T.; Hosaka, K.; Takagaki, T.; Ikeda, M.; Foxton, R.M.; Tagami, J. The effect of five kinds of surface treatment agents on the bond strength to various ceramics with thermocycle aging. Dent. Mater. J. 2017, 36, 55-761. [CrossRef]

8. Yao, C.; Yu, J.; Wang, Y.; Tang, C.; Huang, C. Acidic pH weakens the bonding effectiveness of silane contained in universal adhesives. Dent. Mater. 2018, 34, 809-818. [CrossRef]

9. Yoshihara, K.; Nagaoka, N.; Sonoda, A.; Maruo, Y.; Makita, Y.; Okihara, T.; Irie, M.; Yoshida, Y.; Meerbeek, B.V. Effectiveness and stability of silane coupling agent incorporated in "universal" adhesives. Dent. Mater. 2016, 32, 1218-1225. [CrossRef]

10. Chen, B.; Lu, Z.; Meng, H.; Chen, Y.; Yang, L.; Zhang, H.; Xie, H.; Chen, C. Effectiveness of pre-silanization in improving bond performance of universal adhesives or self-adhesive resin cements to silica-based ceramics: Chemical and In Vitro evidences. Dent. Mater. 2019, 35, 543-553. [CrossRef]

11. Cardenas, A.M.; Siqueira, F.; Malaquias, P.; Gutierrez, M.F.; Reis, A.; Perdigão, J.; Loguercio, A. Effect of MDP-containing silane and adhesive used alone or in combination on the long-term bond strength and chemical interaction with lithium disilicate ceramics. J. Adhes. Dent. 2017, 19, 203-212. [CrossRef] [PubMed]

12. Alrabiah, M.; Labban, N.; Levon, J.A.; Brown, D.T.; Chu, T.-M.; Bottino, M.C.; Platt, J.A. Bond strength and durability of universal adhesive agents with lithium disilicate ceramics: A shear bond strength study. J. Adhes. Sci. Technol. 2018, 32, 580-589. [CrossRef]

13. Da Rosa, W.L.O.; Piva, E.; da Silva, A.F. Bond strength of universal adhesives: A systematic review and meta-analysis. J. Dent. 2015, 43, 765-776. [CrossRef] [PubMed]

14. Murillo-Gómez, F.; Rueggeberg, F.A.; de Goes, M.F. Short- and long-term bond strength between resin cement and glass-ceramic using a silane-containing universal adhesive. Oper. Dent. 2017, 42, 514-525. [CrossRef] [PubMed]

15. Moro, A.F.V.; Ramos, A.B.; Rocha, G.M.; Perez, C.R. Effect of prior silane application on the bond strength of a universal adhesive to a lithium disilicate ceramic. J. Prosthet. Dent. 2017, 118, 666-671. [CrossRef]

16. Taguchi, K.; Hosaka, K.; Ikeda, M.; Kishikawa, R.; Foxton, R.; Nakajima, M.; Tagami, J. The effect of warm air-blowing on the microtensile bond strength of one-step self-etch adhesives to root canal dentin. J. Prosthodont. Res. 2018, 62, 330-336. [CrossRef]

17. Yonekura, K.; Hosaka, K.; Tichy, A.; Taguchi, K.; Ikeda, M.; Thanatvarakorn, O.; Prasansuttiporn, T.; Nakajima, M.; Tagami, J. Air-blowing strategies for improving the microtensile bond strength of one-step self-etch adhesives to root canal dentin. Dent. Mater. J. 2020, 39, 892-899. [CrossRef]

18. Fabianelli, A.; Pollington, S.; Papacchini, F.; Goracci, C.; Cantoro, A.; Ferrari, M.; van Noort, R. The effect of different surface treatments on bond strength between leucite reinforced feldspathic ceramic and composite resin. J. Dent. 2010, 38, 39-43. [CrossRef]

19. Shen, C.; Oh, W.S.; Williams, J.R. Effect of post-silanization drying on the bond strength of composite to ceramic. J. Prosthet. Dent. 2004, 91, 453-458. [CrossRef]

20. De Carvalho, R.F.; Cotes, C.; Kimpara, E.T.; Leite, F.P.P.; Özcan, M. Heat treatment of pre-hydrolyzed silane increases adhesion of phosphate monomer-based resin cement to glass ceramic. Braz. Dent. J. 2015, 26, 44-49. [CrossRef]

21. Monticelli, F.; Toledano, M.; Osorio, R.; Ferrari, M. Effect of temperature on the silane coupling agents when bonding core resin to quartz fiber posts. Dent. Mater. 2006, 22, 1024-1028. [CrossRef] [PubMed]

22. Bakhsh, T.A.; Sadr, A.; Shimada, Y.; Tagami, J.; Sumi, Y. Non-invasive quantification of resin-dentin interfacial gaps using optical coherence tomography: Validation against confocal microscopy. Dent. Mater. 2011, 27, 915-925. [CrossRef] [PubMed]

23. Bista, B.; Sadr, A.; Nazari, A.; Shimada, Y.; Sumi, Y.; Tagami, J. Nondestructive assessment of current one-step self-etch dental adhesives using optical coherence tomography. J. Biomed. Opt. 2013, 18, 76020. [CrossRef] [PubMed]

24. Ekambaram, M.; Yiu, C.K.Y.; Matinlinna, J.P. An overview of solvents in resin-dentin bonding. Int. J. Adhes. Adhes. 2015, 57, 22-33. [CrossRef]

25. Cadenaro, M.; Breschi, L.; Antoniolli, F.; Navarra, C.O.; Mazzoni, A.; Tay, F.R.; di Lenarda, R.; Pashley, D.H. Degree of conversion of resin blends in relation to ethanol content and hydrophilicity. Dent. Mater. 2008, 24, 1194-1200. [CrossRef]

26. Takahashi, M.; Nakajima, M.; Hosaka, K.; Ikeda, M.; Foxton, R.M.; Tagami, J. Long-term evaluation of water sorption and ultimate tensile strength of HEMA-containing/-free one-step self-etch adhesives. J. Dent. 2011, 39, 506-512. [CrossRef]

27. Kuno, Y.; Hosaka, K.; Nakajima, M.; Ikeda, M.; Klein, J.; Foxton, R.M.; Tagami, J. Incorporation of a hydrophilic amide monomer into a one-step self-etch adhesive to increase dentin bond strength: Effect of application time. Dent. Mater. J. 2019, 38, 892-899. [CrossRef] 